\title{
PERANCANGAN MEDIA PENGENALAN WARNA UNTUK ANAK USIA DINI
}

\author{
Yariska Hardiyanti, Muhammad Saleh Husain, Nurabdiansyah \\ Fakultas Seni dan Desain, Universitas Negeri Makassar \\ Yariska0hardiyanti@gmail.com \\ muhsalehhusain@gmail.com \\ Nurabdiansyah@unm.ac.id
}

\begin{abstract}
Abstrak
Perancangan ini bertujuan membuat media pembelajaran untuk anak usia dini dengan memperkenalkan beberapa warna untuk anak dengan menggunakan permainan rubik sebagai media utama. Data didapat dari wawancara pada salah satu guru PAUD dan observasi langsung di sekolah PAUD SPAS desa Parigi. Perancangan yakni, memilih ide, konsep, tema, pemetaan gagasan, membuat sketsa, merancang digitalisasi dengan vector, coloring, tipografi, hingga final desain. Hasil perancangan secara keseluruhan menghasilkan sebuah permainan yang bisa digunakan untuk media pembelajaran. Media ini terdiri dari media utama yaitu rubik balok pocket (mini), dengan media pendukung berupa buku Quiz, stiker, kemasan, notebook, x-banner, dan gantungan kunci.
\end{abstract}

Kata Kunci: Permainan, Rubik, dan Anak Usia dini

\begin{abstract}
This design aims to create learning media for early childhood by introducing some colors for children by using rubik game as the main media. Data obtained from interviews in one of PAUD teachers and direct observation at PAUD SPAS school in Parigi village. Design that is, choosing ideas, concepts, themes, mapping ideas, sketching, designing digitalization with vector, coloring, typography, until the final design. The overall design results produce a game that can be used for instructional media. This media consists of main media that is rubik pocket (mini), with supporting media such as Quiz book, sticker, packaging, notebook, $\mathrm{x}$-banner, and keychain.
\end{abstract}

Keywords: Games, Rubik, and Early Childhood

\section{PENDAHULAN}

Usia dini merupakan usia awal yang paling penting dan mendasar sepanjang pertumbuhan dan perkembangan kehidupan manusia. Pada usia ini memberikan pendidikan sejak dini sangat penting untuk perkembangan kemampuan anak. Penelitian membuktikan memberikan pendidikan anak sejak dini sangat baik karena pendidikan usia dini merupakan dasar untuk tahap tumbuh kembang anak selanjutnya. Suyanto (2005a:1) menyatakan bahwa "pendidikan anak usia dini adalah anak yang berusia $0-8$ tahun yang memiliki karakter yang berbeda dengan anak-anak yang berusia di atasnya sehingga pendidikannya perlu di

khususkan". Berbeda dengan Suyanto, dalam undang-undang Republik Indonesia Nomor 20
Tahun 2003 tentang Sistem Pendidikan Nasional Pasal 1 Ayat 14, Pendidikan Anak Usia Dini adalah upaya pembinaan yang ditujukan kepada anak sejak lahir sampai dengan usia enam tahun yang dilakukan melalui pemberian rangsangan pendidikan untuk membantuh pertumbuhan dan perkembangan jasmani dan rohani agar anak memiliki kesiapan memasuki pendidikan lebih lanjut.

Kemampuan mengenal warna pada anak usia dini merupakan hal yang sangat penting bagi perkembangan otaknya, sebab pengenalan warna pada anak usia dini dapat merangsang indera penglihatan otak. Warna juga dapat memancing. Kepekaan terhadap penglihatan yang terjadi karena warna yang ada pada benda terkena sinar matahari baik secara langsung atau tidak langsung yang 
kemudian dapat dilihat oleh mata. Maka dalam perancangan media pengenalan warna untuk mengenalkan warna kepada anak-anak dengan baik, sehingga mampu menumbuhkan pemahaman tentang warna bermakna dalam situasi yang menyenangkan. Suasana belajar harus diciptakan melalui kegiatan permainan yang sesuai dengan karekteristik anak yang masih senang bermain. Permainan memiliki peran penting dalam perkembangan bahasa, kognitif, fisikmotorik, sosial emosional, nilainilai agama dan moral.

Kemampuan kognitif adalah proses berpikir untuk memperoleh dan menggunakan pengetahuan dalam rangka memecahkan masalah dan beradaptasi dengan lingkungan sekitar. Anak usia dini memiliki kemampuan belajar yang luar biasa terutama pada masa kanak-kanak. Keingintahuan anak untuk belajar menjadikan anak kreatif dan eksploratif. Anak belajar dengan seluruh panca inderanya untuk memahami sesuatu dan dalam waktu yang singkat beralih ke hal lain untuk dipelajari. Karakteristik anak usia dini menjadi hal yang penting untuk dipahami agar memiliki generasi yang mampu mengembangkan diri secara optimal mengingat pentingnya usia emas (The golden age) tersebut. Mengembangkan kreativitas dan pemahaman anak memerlukan peran penting pendidik. Anak kreatif memuaskan rasa keingintahuannya melalui berbagai cara seperti bereksplorasi, bereksperimen, dan banyak mengajukan pertanyaan kepada orang lain. Namun kenyataannya masih banyak anak-anak yang memiliki kreativitas rendah dan pemahaman yang lambat sejak usia dini.

Berdasarkan pengamatan awal di PAUD Spas Desa Parigi yang berjumlah 28 siswa, kreativitas dan pemahaman anak masih perlu ditingkatkan. Dari jumlah siswa yang ada di dalam kelas, terdapat 15 anak yang pada saat ditempel belum sesuai dengan tempat yang disediakan. Kemudian pada saat menggambar, anak-anak masih bingung dalam membedakan beberapa warna, anak-anak masih ada meniru gambar milik teman yang lain dan mewarnainya

sama persis dengan temannya. Dalam kegiatan pembelajaran, anak-anak melakukan kegiatan masih mengikuti pada contoh guru. Pada saat proses pembelajaran, guru menjelaskan masih menggunakan Lembar Kerja Anak (LKA) yang terlalu kecil yang kemungkinan membuat anak kesulitan dalam berkonsentrasi dan kurang menarik bagi anak. Guru juga lebih menekankan pada membaca dan menulis. Metode pembelajaran yang digunakan monoton sehingga membuat anak bosan dan kurang dapat bereksplorasi. Pemberian Lembar Kerja Anak (LKA) yang terlalu sering juga membuat anak merasa bosan dan jenuh. Permainan media balok rubik mini atau cube mini juga masih belum digunakan di Taman Kanak-kanak Seatap atau belum familiar di anak-anak, dimana hal ini dapat memberikan hal baru kepada anak-anak dalam mengembangkan pengetahuan dan kreativitas anak. Dengan uraian permasalahan diatas penelitian ini adalah "Perancangan Media Pengenalan Warna Untuk Anak Usia Dini”.

Berdasarkan latar belakang masalah, muncul berbagai masalah yang teridentifikasi seperti: 1) Terdapat beberapa jenis media, 2) pengenalan warna yang medianya kurang menarik, 3) Beberapa anak sekarang kurang kreatif dan pemahaman yang lambat atau kurang karena media yang digunakan monoton.

Berdasarkan identifikasi masalah maka dapat dirumuskan masalah sebagai berikut; 1) Bagaimana menampilkan media yang menyenangkan tentang pengenalan warna bagi anak usia dini? 2) Bagaimana menciptakan media pengenalan warna yang dapat mengembangkan dan membantu mempermudah pemahaman anak-anak untuk warna serta huruf dan gambar?

Tujuan Perancangan Berdasarkan dari latar belakang dan identifikasi masalah tersebut, maka tujuan perancangan adalah membantuh orang tua dan guru taman kanakkanak dalam memperkenalkan 12 warna serta namanya, angka, huruf, mengenal gambar buah, benda dan namanya.

Manfaat Perancangan; 1) Bagi orang tua dan Guru: Sebagai media pendidikan pengenalan warna serta, huruf, angka, buah, dan benda untuk anak, 2) Bagi anak Dapat mengenal macam warna serta huruf, angka, buah, benda dan meningkatkan kreativitas dan daya pikir yang berpengaruh pada perkembangan intelektual yakni kemampuan mengingat.

Yuliani Nurani Sujiono (2009:8) mengatakan "Stiumulasi dapat membantu 
pertumbuhan dan perkembangan jasmani dan rohani agar anak memiliki kesiapan dalam memasuki pendidikan lebih lanjut". Depdiknas (2007:1) usia 0-6 tahun merupakan usia emas (The golden age) yaitu masa peka yang hanya dating sekali. Masa peka adalah masa perkembangan anak dikembangkan secara optimal. Slamet Suyanto (2005:1) menyatakan bahwa "Pendidikan anak usia dini adalah anak yang berusia $0-8$ tahun yang memiliki karakter yang berbeda dengan anak-anak yang berusia di atasnya sehingga pendidikannya perlu dikhususkan". Berbeda dengan Slamet Suyanto, dalam Undang-Undang Republik Indonesia Nomor 20 Tahun 2003 tentang sistem pendidikan nasional pasal 1 ayat 14 , pendidikan anak usia dini adalah upaya pembinaan yang ditujukan kepada anak sejak lahir sampai dengan usia 6 tahun yang dilakukan melalui pemberian rangsangan pendidikan untuk membantu pertumbuhan dan perkembangan jasmani dan rohani agar anak memiliki kesiapan memasuki pendidikan lebih lanjut. Usia dini merupakan masa sensitif anak untuk menerima berbagai upaya perkembangan seluruh potensi anak. Masa peka atau masa sensitif adalah masa dimana terjadi kematangan fungsi-fisik dan psikis yang siap menrespon stimulasi yang diberikan oleh lingkungannya, karena pada usia ini peluang perkembangan anak sangat berharga maka peran orang tua adalah memberikan stimulasi dan memantau secara terus menerus agar dapat lebih cepat mengetahui aspek-aspek perkembangan yang sudah dicapai oleh anak.

Seperti yang dikemukakan Rasyid (2009:1) bahwa "Perkembangan anak usia dini harus dipantau secara terus menerus sehingga akan cepat diketahui kematangan dan kesiapan, baik yang menyangkut perkembangan kemampuan lainnya yang akan membentuk karakter mereka kelak".

Aspek-aspek perkembangan tersebut tidak berkembang secara sendiri-sendiri melainkan saling terintegrasi dan saling berhubungan antara perkembangan tersebut, perkembangan satu dengan yang lainnya. Dari beberapa aspek perkembangan tersebut, perkembangan kognitif adalah salah satu aspek penting yang harus dikembangkan untuk kemampuan berpikir anak. Marlianti (2012:23) mengatakan hal ini agar anak dapat mengelola perolehan belajarnya, memecahkan masalah, membantu anak untuk mengembangkan kemampuan logika matematika dan pengetahuan akan ruang dan waktu, serta mempersiapkan pengembangan kemampuan berpikir teliti.

Mengatakan senada dengan pendapat sebelumnya Susanto (2011:48) mengatakan bahwa "Proses kognisi meliputi berbagai aspek seperti persepsi, ingatan, pikiran, simbol, penalaran, dan pemecahan masalahmasalah". Dengan demikian perkembangan kognitif merupakan aspek yang sangat penting untuk dikembangkan karena melalui perkembangan kognitif anak dapat memperoleh kemampuan dalam berpikir, memecahkan masalah dan mengembangkan kemampuan logika dalam perkembangan anak selanjutnya.

Kemampuan mengenal warna merupakan salah satu aspek dari kemapuan kognitif. Pengenalan warna pada anak usia dini dapat merangsang indera penglihatan otak. Warna juga dapat memancing kepekaan terhadap penglihatan yang terjadi karena warna yang ada pada benda terkena sinar matahari baik secara langsung atau tidak langsung yang kemudian dapat dilihat oleh mata, seperti pendapat Fudyartanta (2011:195) bahwa proses pengindraan mata terjadi melalui fase-fase sebagai berikut: "a). Saat face fisis jalannya perangsangan dari benda sampai pada mata, artinya pada saat cahaya sampai pada kornea mata diteruskan melalui lensa mata sampai pada bintik kuning pada retina. b) Fase psikis yaitu jalannya perangsangan di dalam badan, prosesnya saat mata melihat benda (warna benda) diteruskan ke urat saraf mata dan kemudian sampai ke otak (pusat penglihatan) dan, c) Psikis yaitu jalannya terjadi penginderaan atau pengetahuan tentang objek, dalam hal melihat objeknya adalah warna benda, disini tidak ada perangsangan lagi, hanya kesadaran bahwa kita melihat warna benda tersebut".

Saat psikis inilah reaksi jiwa dengan alat inderanya atas penusukan otak oleh perangsangannya. Selain dapat merangsang indera penglihatan, pengenalan warna juga meningkatkan kreativitas anak dan daya pikir yang berpengaruh pada perkembangan intelektual yakni kemampuan mengingat. Oleh sebab itu mengenal warna sejak dini sangat dianjurkan agar anak dapat membedakan dan 
mengetahui macam- macam warna dasar dan komplemennya.

\section{METODE}

Metode pengumpulan data merupakan teknik atau cara yang dilakukan untuk pengumpulan data. Dalam hal ini, data yang dihasilkan di kelompokkan menjadi 2 (dua) jenis yaitu data primer yang diperoleh dengan tindakan secara langsung dan data sekunder yang diperoleh dari kajian pustaka.

\subsection{Data Primer}

\subsubsection{Wawancara}

Mewawancarai guru PAUD di Desa Parigi, wawancara dipersiapkan secara matang dan dilakukan secara terstruktur serta sistematis. Wawancara dilakukan dengan narasumber ibu Hasmawati selaku guru yang mengajar, serta menggunakan strategi tanya jawab secara lisan dan jawaban akan dicatat.

\subsubsection{Observasi}

Penulis melakukan observasi di Kabupaten Gowa, tepatnya di PAUD Spas Desa Parigi. Tujuan dilakukannya observasi ini adalah untuk mengetahui jenis produk atau media pembelajaran tentang pengenalan warna yang digunakan untuk membantu mengembangkan pemahaman, kreativitas, serta kognitif anak tentang warna.

\subsubsection{Dokumentasi}

Teknik pengumpulan data dengan metode dokumentasi adalah pengambilan data melalui dokumen- dokumen atau catatan yang terkait dengan permasalahan yang akan diteliti, studi dokumentasi digunakan sebagai pelengkap dari penelitian ini. Dengan adanya dokumentasi maka gambar yang sangat diperlukan salah satu bukti fisik dalam pengumpulan data.

\subsection{Data Sekunder}

\subsubsection{Kajian Pustaka}

Pada proses ini dilakukan kajian-

kajian literatur yang berhubungan dengan pengenalan tentang warna untuk anak usia dini, yang berguna untuk mengetahui segala aspek tentang media pengenalan warna untuk anak usia dini mulai dari macam-macam media pengenalan warna, jenis-jenis warna, serta cara meningkatkan kognitif anak, kreatifitas, dan pemahaman anak tentang warna.

\subsection{Analisis Data}

\subsubsection{Identifikasi Masalah Perancangan}

Berdasarkan hasil pengumpulan data yang telah diuraikan sebelumnya, maka dapat diidentifikasi masalah perancangan sebagai berikut.

1. Bagaimana membuat sebuah media pengenalan warna untuk anak usia dini secara efektif agar dapat menghasilkan media pembelajaran yang tepat sasaran?

2. Bagaimana cara merancang media pengenalan warna untuk anak usia dini melalui media permainan rubik balok agar pesan yang terkandung didalamnya dapat dipahami oleh targer audience?

3. Bagaimana agar pesan bisa tersampaikan ke target audience?

\subsubsection{Batasan Masalah Perancangan}

Berdasarkan identifikasi masalah perancangan yang telah diuraikan, maka dapatbatasan masalah dalam perancangan meliputi:

1. Materi yang digunakan adalah:

a. Warna primer dan beberapa warna yang sudah dikenal anak atau sering ditemui dan batasannya adalah hanya menggunakan 12 warna yaitu merah, kuning, biru, hitam, merah muda, oranges, biru muda, ungu, coklat, coklat muda, abu-abu, dan hijau.

b. Huruf mulai dari A sampai $\mathrm{Z}$

c. Angka mulai dari 1 sampai 40

2. Media ini diperuntuhkan untuk anak usia 4-6 tahun.

3. Mengingat target audiencenya adalah anak- anak maka keamanan permainan juga sangat penting untuk diperhatikan.

4. Perancangan media pembelajaran ini menggunakan media permainan rubik.

\section{HASIL DAN PEMBAHASAN}

\subsection{Pra Perancangan}

Pra perancangan merupakan tahap awal untuk memulai perancangan dengan 
proses yang dilakukan mulai dari curah ide/brainstorming, gagasan/mind mapping, konsep, tema, materi, sumbe rinspirasi, dan sketsa. Seperti dibawah ini;

\subsubsection{Curahan Gagasan/Brainstorming}

Ide atau gagasan adalah sebuah ide yang mendasar dari suatu pokok masalah yang kemudian dicurahkan dan suatu aspek ide mendasar yang diangkat pada perancangan media pengenalan warna untuk anak usia dini yaitu merancang media yang menyenangkan untuk belajar sambil bermain buat anak usia dini.

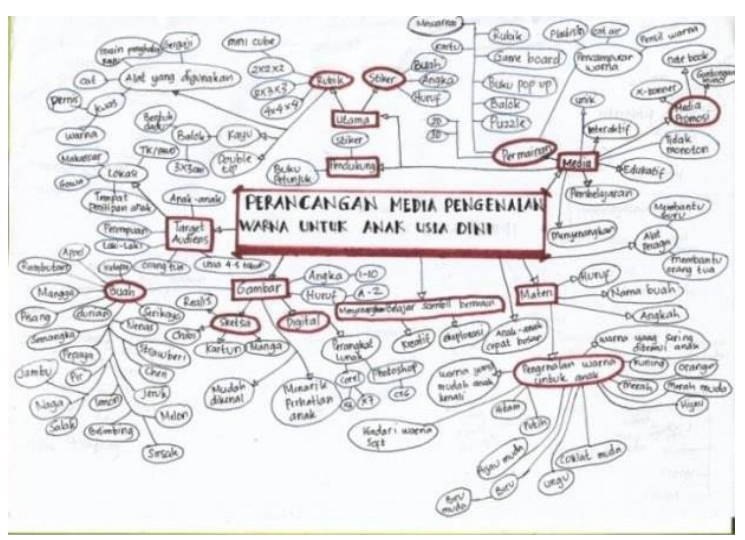

Gambar 3.1 Curahan Gagasan/Brainstrorming (Foto: Yariska, 07 Maret 2018, Scan)

\subsubsection{Pemetaan Gagasan/Mind Mapping}

Dari hasil pemetaan gagasan pada mind mapping bias dilihat yang akan dibuat yaitu perancangan media pengenalan warna untuk anak usia dini. Seperti yang terdapat dibawah ini:

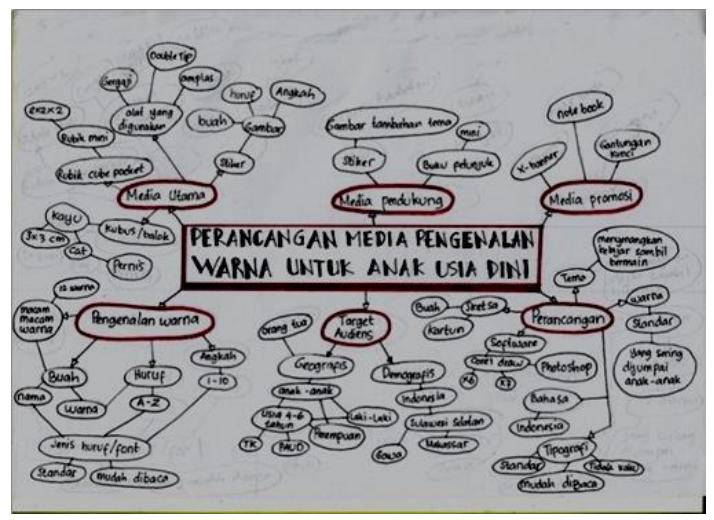

Gambar 3.2 Pemetaan Gagasan / Mind Mapping (Foto: Yariska, 07 Maret 2018, Scan)

\subsection{Eksplorasi Visual / Visual Eksploration (Sketching)}

\subsubsection{Media Utama}

Media utama menggunakan balok yang akan dipotong dengan ukuran $5 \mathrm{~cm}$ x $5 \mathrm{~cm}$. dan akan dibuatkan sebanyak 12 rubik untuk setiap warna.

\section{a) Sketsa Bentuk Rubik}

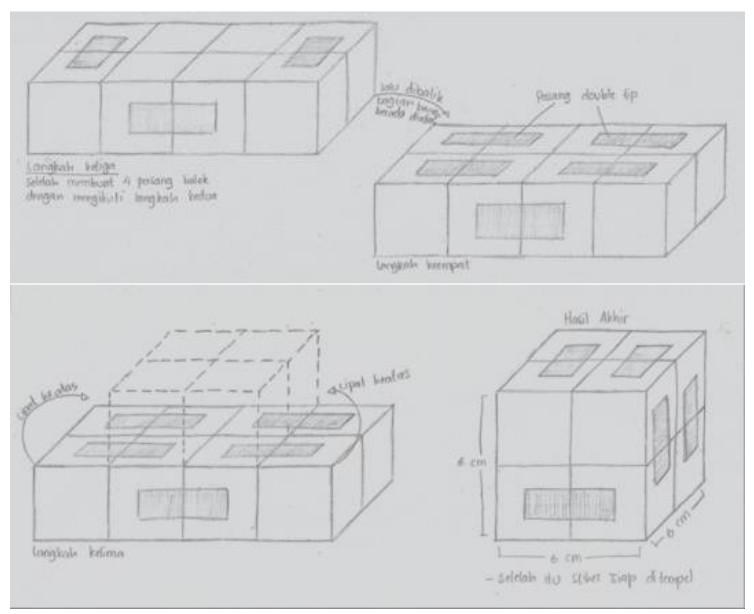

Gambar 3.3 Sketsa tahap lanjutan pembuatan media utama

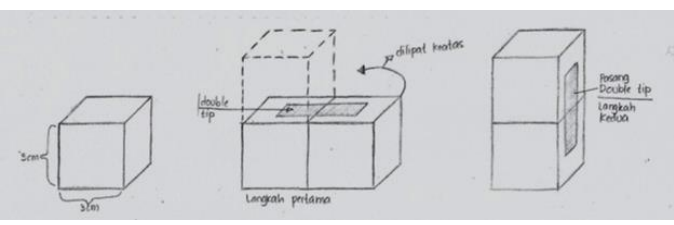

Gambar 3.4 Sketsa proses pembuatan media utama

b) Sketsa Desain untuk tiker/gambar untuk setiap sisi rubik

Dibagian ini selain warna merah seperti gambar yang ada di bawah akan dibuatkan juga untuk warna lainnya.

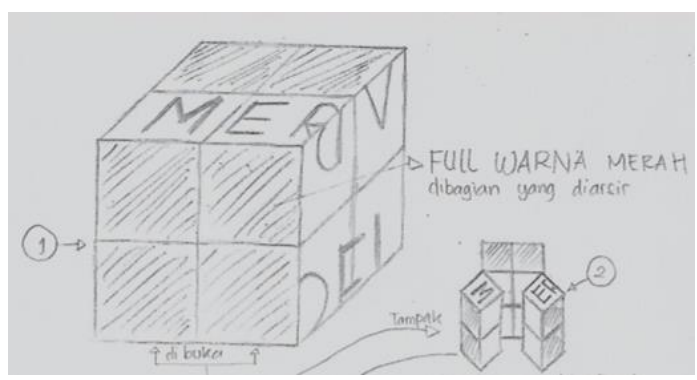

Gambar 3.5 Sketsa stiker full warna merah dan penempatan sisinya 


\subsection{Media Utama, Media Pendukung dan Media Promosi}

\subsubsection{Media Utama}

Media utama yaitu balok yang ukurannya 5 × $5 \mathrm{~cm}$ yang nantinya akan disusun. Media balok ini merupakan variasi antara rubik dan permainan balok selain itu untuk memperkenalkan huruf, angka, dan buah-buahan yang ada di Indonesia. Jenis balok yang digunakan yaitu jenis kayu ringan dan kuat. Yang nantinya dibuat menjadi rubik pocket yang merupakan rubik jenis mini/rubik $2 \times 2 \times 2$.

\subsubsection{Media Pendukung}

Media pendukung yaitu berupa buku Quiz, kemasan, dan gambar/stiker yang disertai dengan huruf dan angka yang akan ditempelkan ke balok tersebut

\subsection{Perancangan Digitalisasi \\ 3.4.1. Media Utama}
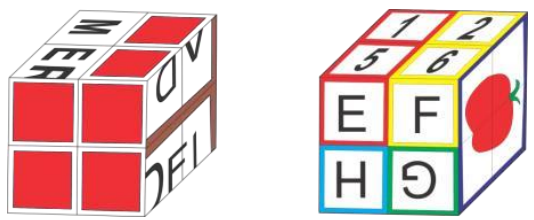

Gambar 5.6 Digital gambar media Utama

\subsubsection{Media Pendukung}

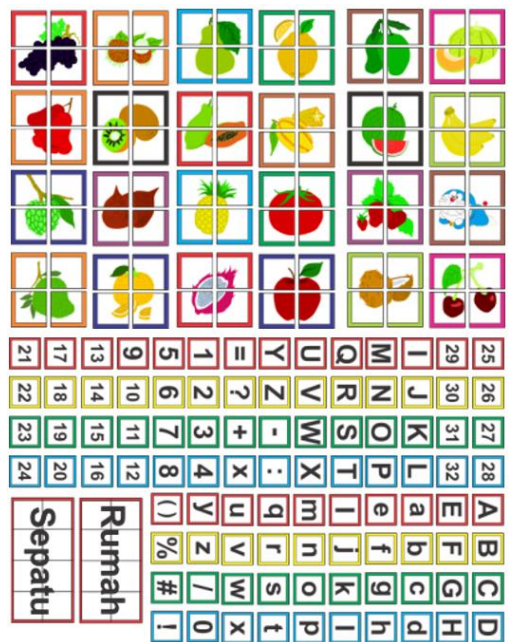

Gambar 5.7 Digital gambar media pendukung Stiker buah, huruf, dan angka
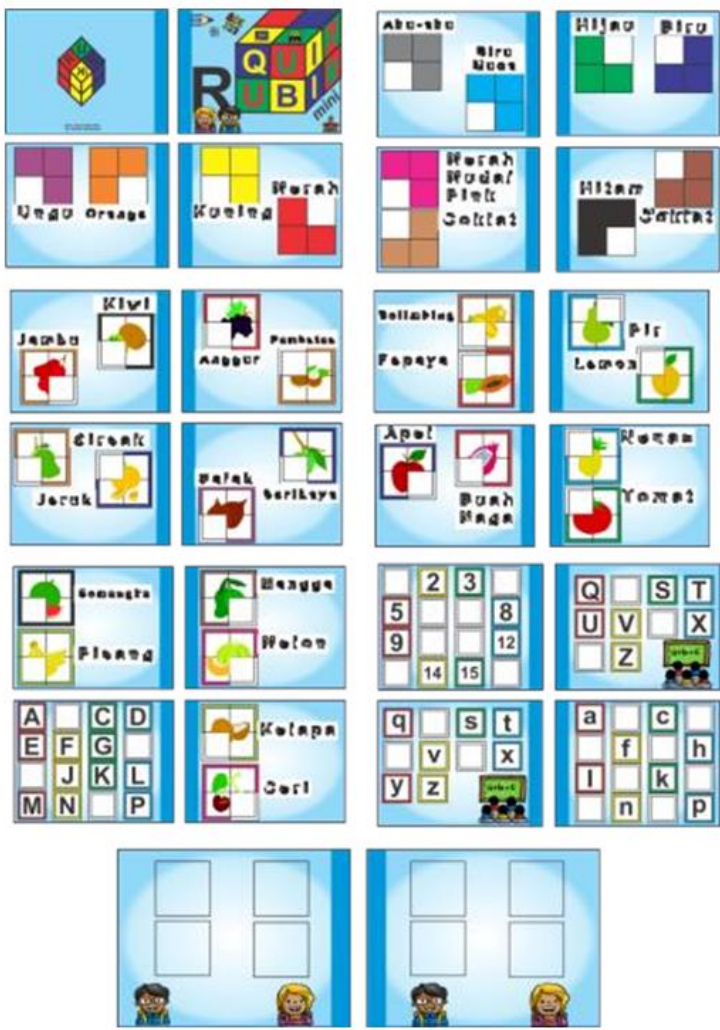

Gambar 6.1 Digital gambar media pendukung Buku quiz serta isinya

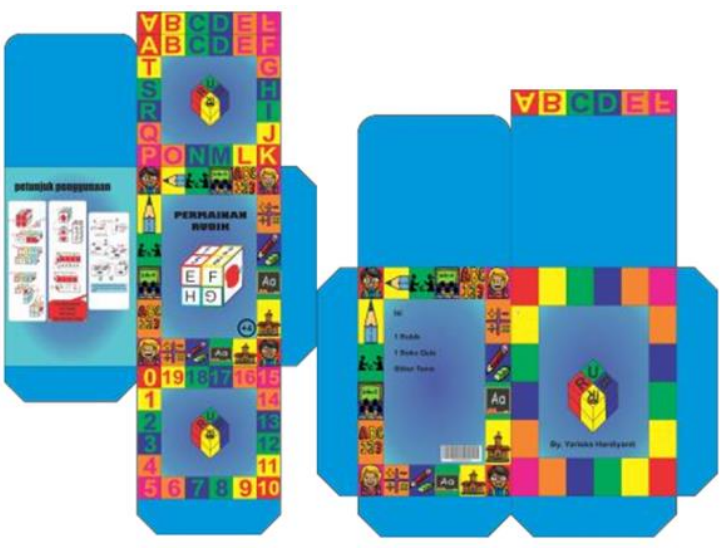

Gambar 6.2 Digital gambar media pendukung Kemasan

\subsection{Perancangan Final}

\subsubsection{Media Utama}

Media utama pada perancangan media pengenalan warna untuk anak usia dini adalah sebuah rubik dengan ukuran $10 \mathrm{~cm}$ x $10 \mathrm{~cm}$ dimana rubik tersebut menggunakan potongan balok berukuran $5 \mathrm{~cm}$ dan di lengkapi dengan gambar, huruf, buah, benda dan angka. 


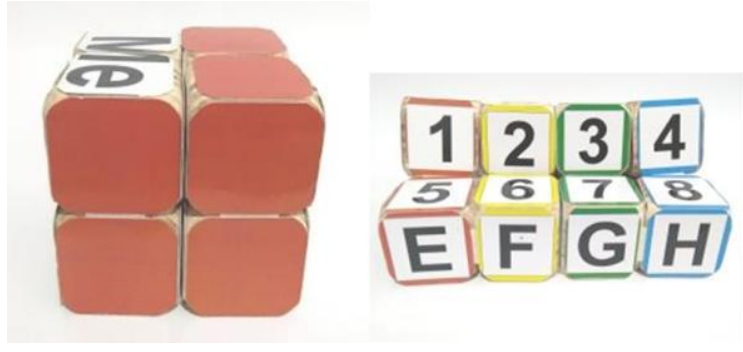

Gambar 6.4 Hasil jadi Rubik

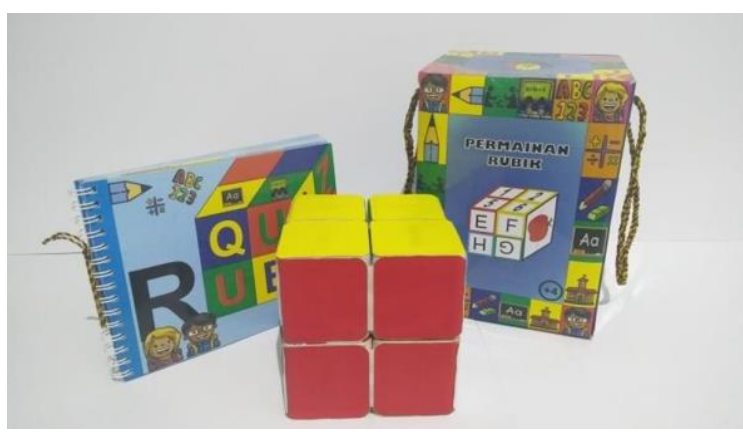

Gambar 6.5 Hasil jadi Keseluruhan

\section{SIMPULAN DAN SARAN}

media

Berdasarkan hasil "Perancangan

pengenalan warna untuk anak usia dini" yang menghasilkan desain media edukasi sekalian permainan untuk anak usia dini, maka dapat ditarik kesimpulan sebagai berikut:

1. Dalam perancangan media pengenalan warna untuk anak usia dini, menghasilkan sebuah permainan rubik dengan materi warna, angka, huruf, buah, benda, nama warna, dan nama buah. Dalam 1 rubik terdapat materi untuk 4 kotak yaitu 1 warna, 2 jenis gambar buah, dan 1 jenis gambar benda. Untuk 8 kotak yaitu huruf A sampai $\mathrm{z}$, angka 1 sampai 8 , ejaan "apel", warna dan namanya. Jenis warna yang digunakan hanya ada 12 warna yaitu merah, kuning, biru, hijau, coklat, hitam, merah muda, ungu, biru muda, abu-abu, oranges, coklat muda. Untuk angka dibatasi hanya dari 1 sampai 40 serta $+, \mathrm{x},-,=, /$, dan ?, sedangkan buah hanya 23 jenis saja, dan benda 6 jenis serta ejaannya masing-masing, nama warna, buah, dan benda.

2. Perancangan media pengenalan warna untuk anak usia dini ini dalam satu kemasan dilengkapi dengan media pendukung seperti buku Quiz, dan tema tambahan (Stiker) seperti angka 9 sampai 40, huruf I sampai Z, 11 jenis warna dan namanya, 21 jenis gambar buah dan namanya, dan 5 jenis gambar benda namanya.

\section{REFERENSI}

Azhar, Arsyad. 2011. Media Pembelajaran. PT Raja grafindo Persada, Jakarta.

Bandru, Zaman, dkk. 2009. Media dan Sumber Belajar TK. Jakarta: Universitas terbuka.

Budiningsih, Asri. 2004. Belajar dan Pembelajar. Yogyakarta: Rineka Cipta.

C, Asri Budiningsih. 2004. Belajar dan Pembelajaran. Yogyakarta: Rineka Cipta.

Darmaprawira, Sulasmi. 1989. Warna Sebagai Salah Satu Unsur Seni \& Desain. Jakarta: Departemen Pendidikan dan Kebudayaan.

-. 2002. Warna Teori dan Kreatifitas Penggunaannya. Bandung: Institut Teknologi Bandung.

D, Cambell. 1997. Mengembangkan Kreativitas. Yogyakarta: Kanisius.

David, Fred R. 2005. Menejemen Strategis Konsep. Jakarta: Salemba Empat.

Departemen Pendidikan Nasional. 2003. Undang-Undang Republik Indonesia No.20 Tentang Sistem Pendidikan

Nasional. Bandung: Citra umbara. Depdiknas. 2005. Pedoman Pembelajaran di Taman Kanak-Kanak. Jakarta: depdiknas.

Depdiknas. 2007. Pedoman Pembelajaran Bidang Pengembangan Berbahasa di Taman Kanak-Kanak. Jakarta: Balai Pustaka.

Fudyartanta, Ki. 2011. Psikologi Umum I \& II.

Yogyakarta: Pustaka Pelajar. Hakim, Rustam \& Hardi Utomo. 2003.

Arsitektur Landsehap. Jakarta: Bumi Aksara.

Hasan, Maimunah. 2009. Pendidikan Anak Usia

Dini. Yogyakarta: Diva Press. Izzaty, Rita Eka, dkk. 2008. Pengembangan Peserta Didik. Yogyakarta: Universitas Negeri Yogyakarta.

John, W Santrock. 2007. Perkembangan Anak. (ahli bahasa Mila Rachmawati\& Anna 


\section{imajinasi}

Kuswanti). Jakarta: Erlangga. Latif, Dkk. 2003. Orientasi Baru Pendidikan Anak Usia Dini. Jakarta: Kencana Prenada Media Grup.

Mansur. 2005. Pendidikan Anak Usia Dini dalam Islam. Yogyakarta: Pustaka Pelajar.

Montolalu. 2005. Bermaindan Permainan Anak. Jakarta: Universitas Terbuka.

Mustofa, Yasin. 2007. EQ untuk Anak Usia Dini dalam Pendidikan Islam. Jakarta: Seketsa.

Pujiriyanto. 2005. Desain Grafis Komputer (Teori Desain Grafis Komputer). Yogyakarta: CV. Andi Offset.

Rasyid, Harun, Mansyur, \&Suratno. 2009. Asesmen Perkembangan Anak Usia Dini. Yogyakarta: Multi Pressindo.

Said, Asis. 2014. Logo. Makassar: Badan Penerbit UNM Makassar.

Sanyoto, Sadjiman Ebdi. 2005. Dasar-Dasar Tata Rupa dan Desain. Yogyakarta: CV Arti Bumi Intaran.

Sugihartono, dkk. 2007. Psikologi Pendidikan. Yogyakarta: Universitas Negeri Yogyakarta Press.

Sujiono, Yuliani Nurani. 2009. Konsep Dasar Pendidikan Anak Usia Dini.Jakarta: PT Indeks.

Suparno, Paul. 2001. Teori Perkembangan Kognitif Jean Piaget. Yogyakarta: Kanisius.

Susanto, Ahmad. 2011. Perkembangan Anak Usia Dini. Kencana Prenada Media Group. Jakarta.

-. 2012. Perkembangan Anak Usia Dini. Jakarta: Kencana.

Suyanto, Slamet. 2005 (a). Dasar-dasar Pendidikan Anak Usia Dini. Yogyakarta: Hikayat.

Suryadi. 2010. Psikologi Belajar PAUD, Pedagogia. Jakarta.

Tedja saputra, Mayke S. 2005. Bermain, Mainan, dan Permainan. Jakarta: Grasindo.

Yudha, Saputra M \& Rudyanto. 2005. Pembelajaran Kooperatif untuk Meningkatkan Keterampilan Anak TK. Jakarta: Departemen Pendidikan Nasional.

Nento, Serfi. 2013. Mengembangkan Kemandirian Anak melalui Bermain Balok di Kelompok Bermain Melati
Desa Bulalo Kecamatan Kwandang Kabupaten Gorontalo Utara. Tesis tidak diterbitkan. Gorontalo: Universitas Negeri Gorontalo.

Marlianti, Neti. 2012. Penggunaan Metode Karyawisata untuk Meningkatkan Kemampuan Mengenal Warna pada Anak TK. (Online) (http://repository.upi.edu/operator/upl oad/s_paud_1007642_chapter1.pdf,dia kses 16 Juni 2017).

Suratno. 2005. Konsep Kemampuan Sumber Daya Manusia. (Online) (http://sulut.kemenag.go.id/file/file/ke pegawaian/aunw1341283316.pdf, diakses 17Juli 2017). 